\title{
Conceptual Framework for Calculation of Climate Performance with Pre-verified LCA-Tools
}

\author{
Larissa Strömberg \\ NCC (Nordic Construction Company), Solna 170 80, Sweden
}

\begin{abstract}
This article proposes the use of current European standards and verification rules for EPDs (environmental product declarations) as a basis for evaluating the climate impact of contractors' alternative designs of infrastructural projects. The proposed conceptual framework for verified climate calculations is based on the Swedish-based, the International EPD ${ }^{\circledR}$ System. Several Swedish and Norwegian stakeholders were engaged in this joint project to understand driving forces and obstacles and provide key insights for the successful implementation of the framework for a transparent and comparable assessment of climate impact from alternative design options. In order to perform a sharp test of some main hypothesizes, the project participants tested the proposed framework in bridge and roads projects.
\end{abstract}

Key words: Climate calculation, inventory data collection, EPD (environmental product declaration), LCA software, infrastructural project.

\section{Introduction}

Sweden faces major challenges in the climate field where the government and parliament now have taken the initiative with the goal of Sweden as a nation to be climate neutral by 2050 [1]. An active involvement of various market players is necessary to manage with the adoption of this goal to the practical work in infrastructural projects. With this background the major Swedish client of infrastructural projects, the STA (Swedish Transportation Administration, Trafikverket) has established requirements for suppliers and contractors regarding energy and climate gas emissions accounting and reporting.

Current reporting of climate efficiency to the STA in infrastructural projects takes place after the tender documentation has been submitted and is a part of the contract requirements. STA uses a default calculation of the climate impact for the project, for the main building materials and construction parts, based on generic industry wide-used emission factors. The

Corresponding author: Larissa Strömberg, Ph.D., research fields: civil and environmental engineering. E-mail: larissastromberg@hotmail.com. contractors and the suppliers then need to streamline this default traditional engineering solution to reach a better environmental performance.

Therefore, a key factor to achieve these client's requirements is to establish a fair and standardized procedure for calculation of the actual project-specific climate impact of the contractors' innovative solutions in different project phases. This calculation procedure should support the establishment of a business-to-business relation between different market stakeholders to reduce the actual project-specific climate impact by developing new innovative products. It will create a great socio-economic improvement if we can match the suppliers' and the contractors' internal investments to more environmentally friendly innovative solutions and the client's evaluation of the design option, e. g. in the tendering process. The using a generic industry-average LCA (life cycle assessment) data for the evaluation of the climate impact of contractors' design solutions, will lead to the sub-optimization and probably to an unfair comparison.

There are some contractors in Sweden which already conduct LCAs in order to improve project's 
climate performance. However, LCAs can be conducted in many ways and if using different system boundaries, different assessment methods, and the way to model the entire life cycle the results will be incomparable. At present, LCAs and climate calculations are not standardized and are performed in different ways, in different commercial LCA-software with different LCA-methods. The current lack of a comparable reliable industry wide-used is anticipated to become an important barrier to improve the actual climate performance of infrastructural projects.

An industry-wide standardized LCA-calculation framework would make it possible to create an unbroken information flow with LCA-data between material suppliers, contractors and clients. A common ground would allow the use of the same LCA-data for various purposes such as a company's internal monitoring of the climate performance in infrastructural projects, internal product development, purchasing of building materials, monitoring for the environmental management system, public procurement, creation of business strategies, reporting according to building assessment schemes, e.g., BREEAM (BRE Environmental Assessment Method), LEED (Leadership in Energy and Environmental Design) and DGNB (Deutsche Gesellschaft für Nachhaltiges Bauen, etc.) and reporting to clients.

At the same time, an EPD (environmental product declarations) is a verified and registered declaration that communicates transparent and comparable information about the life-cycle environmental impact of products or services. EPDs for building materials and building parts based on LCA have been increased on the Nordic market in recent years. However, knowledge and experience of using such standardized climate calculations according to the EPD-format is still very low. In Sweden, the STA starts to encourage contractors to use project-specific EPDs as a verification of project's actual climate impact since spring 2016 [2]. Product-specific EPDs are also required for public procurement in some major projects in Norway [3], by a few municipalities in Sweden and in the international building assessment schemes (LEED, BREEAM, etc.).

Many building material manufacturers have now developed EPDs for their products in order to verify products' environmental performance. However, the "middle" chain in the communication between the material manufacturers and the client, the contractor, has not yet started to produce verified LCAs in EPD-format for infrastructural projects. There is not any general acceptance of EPDs as an industry-wide standard. To achieve the Swedish climate reduction goal, contractors should be stimulated and rewarded for using of innovative environmentally-friendly materials/solutions with verified and documented environmental performance.

The following driving forces for using a standardized LCA-calculation for evaluation in an EPD-format have been identified:

- achieve multiple customer requirements, e.g., building assessment schemes' requirements, internal product development etc., with less cost;

- choice of material suppliers, based on environmental performance of ther products;

- easier to win a bid with a well-established process for EPDs;

- marketing communication with environmental product declarations (EPDs);

- identify most environmentally sensitive components and processes in a company's product portfolio and work strategically with internal improvement;

- be able to steer towards increasing renewable and recycled content in building products and civil engineering projects, which is required by the EU-directives;

- be able to meet future EU requirements with a well-established control of the climate performance of infrastructure projects. 


\section{Methods}

\subsection{The Joint Project}

The joint project organization has been formed by several contractor companies, building material manufacturers, branch organizations and clients. Different stakeholders from some major Nordic building companies, some public clients and municipalities, industry joint organizations have participated at this joint project.

\subsection{Goal and Scope}

The main goal of this joint project was to develop a conceptual framework for calculation of climate impact from infrastructural constructions as bridges and roads in a comparable EPD-format. The scope was to investigate difficulties and driving forces to deliver comparable climate calculations in an EPD-format using data from currently used project planning IT-systems in building companies.

\subsection{Conceptual Framework}

In scope of this joint project was defined a need for an industry-wide framework for carbon emission calculations, which can support entrepreneurs and other actors to perform a calculation of the actual climate impact in the early project stage and gradually improve climate performance throughout the project. One challenge for that is to be able to plan for the reduction of climate impact already in the early planning stage where detailed knowledge of solutions and purchased material is missing. A key component of a LCA-calculation in an EPD-format is the method description document, referred to as PCR (product category rules). A PCR defines the inventory data collection, the LCA-model, the calculation method and requirements on the used LCA-software and LCA-databases [4]. A third part verification is required for approval of an EPD.

The verification process according to the International EPD $^{\circledR}$ System [4] requires using some predefined principles for a carbon calculation. These calculation principles can be applied to different LCA software in order to produce comparable calculation results. The general verification rules in a PCR do not describe all details on calculation steps or data collection principles for carbon calculation for an infrastructure project.

Applying a specific PCR to make comparison of different project alternatives, it is crucial to develop an industry joint framework on definitions and assumptions for carbon calculation. The same system boundaries and data quality should be applied into such industry joint framework to allow the using different commercial LCA-software. To achieve a comparable inventory data collection for an infrastructural project, the data should to be broken down to various building components and material according to the EN 15978 [5]. The different input and output flows in a performed LCA should be connected to specific project's stages, e.g., the building material production, the use phase, etc. according to EN 15804 [6]. The same method for assessment of caused impact to different environmental categories, e.g., the CML-method (method, which was developed by Instititute of Environmental Sciences in The Netherlands) is recommended to use $[7,8]$.

An important question is how to include the climate impact of the operation and maintenance in the LCAs. The supplier should get credit for using of innovative solutions and products without any maintenance alternatively with shorten the service life. It is not enough to calculate the climate impact only from the material production (Modules A1-A3), since maintenance and operation actions (Modules B1-7) are planned for the entire construction or the construction part and seldom at the material level. Contractors can control this part of the construction process and can contribute with more accurate inventory data for the Modules A4-C4. Using environmental assessment only for the Modules 
A1-A3 in the evaluation of alternative contractor' designs may lead to the sub-optimization.

There was a request from the companies involved in this joint project to develop LCA-calculation frameworks for various contract types. The joint LCA-calculation framework can be used in different commercial LCA software. However, this requires a verification procedure for evaluation of used LCA software in order to produce carbon calculation according to the made assumptions in the calculation framework.

\subsection{Pre-verification of a LCA-Tool}

The Swedish-based, the International EPD ${ }^{\circledR}$ System has established a pre-verification procedure for evaluation of existing commercial LCA -tools in order to produce comparable verified EPDs and climate declarations. A pre-verification of a digital LCA-tool to produce EPDs does not replace the single EPD-verification, but it makes the verification procedure simpler as the tool has been pre-verified to conduct comparable LCAs in accordance with a specific PCR.

For the pre-verification of a digital LCA-tool, based on a specific PCR, e.g., for bridges or roads, following functions in the tool and outside of the tool are required by the Swedish operator for EPD-system, Environdec [4]:

- checking of few examples with input data for climate calculations (a material recipe or so-called bill of materials, BoM);

- used LCA-databases must be approved, verified and structured according to EN 15804;

- verification of links between building materials, machinery, etc., in the BoM and emission factors in the used LCA database ;

- control of the used system boundaries for the LCA-model in the used LCA software (according to PCR and EN 15804);

- monitoring of the final EPD-report;

- the LCA software should be pre-verified in advance by the EPD-operator (e.g., Environdec).

\section{Results}

\subsection{Conceptual Framework for Verified Climate Calculations}

The project has developed a conceptual framework, which complete the general verification rules according to the Swedish-based, the International EPD $^{\circledR}$ System. The verification process according to the International EPD ${ }^{\circledR}$ System requires using some predefined principles for carbon calculation. The project participants completed the existed general recommendation for a pre-verification of a digital LCA-tool in order to produce comparable climate declarations and EPDs for infrastructural constructions and projects.

\subsection{Implementation of Some Verification Steps}

In this joint project, several participated contractors tested the data collection process and recommended by PCRs the LCA-calculation method $[5,6]$.

The workflow to produce verified climate calculations in an EPD-format starts with the BoM-template preparation (Fig. 1). The pre-verification of a digital commercial LCA-tool requires the checking of the inventory data collection for an LCA. In this joint project, an Excel-based template for preparation of a BoM with a pre-configured input structure was created. The BoM data was then collected for four infrastructural projects from the participated companies' project cost estimation IT-systems. Each participant collected life cycle inventory data for the selected infrastructure in the developed Excel-based template (BoM template).

Next, it has to be selected or created a mapping of the BoM's items to emissions factors in an LCA-database. The LCA-calculation method should be chosen as well. Then the calculation results should be presented in the pre-defined Word-template for an EPD-report. The joint project has also developed a 
pre-configured Word template with a standard report layout according to the EPD-format. This Word-template was used for the final EPD-report (Fig. 1).

The implementation of these verification steps have been done with help of Thinkstep's LCA-software, LCA Service [9]. These steps can be applied to other LCA-tools as well. The project participants tested to perform the verified calculate calculations in order to calculate the climate impact for four infrastructural projects. This joint project was mainly concentrated to identify obstacles and key insights for the successful implementation of existing standards on EPD and PCRs to climate calculation on companies' ongoing infrastructure projects.

\subsection{System Boundaries}

The functional unit for the pilot project was one piece of infrastructure. For this reason, the collected data has to be entered in the corresponding BoM for one piece of infrastructure (either one bridge or one road). All life cycle phases (materials preparation, construction, operation/maintenance and end-of-life) can be covered in this BoM template depending on what is specified in the infrastructural project. The system boundaries considered as default in the delivered BoM template are described in Fig. 2.

The main intention with the Excel-based BoM template for data collection was that each user can modify this BoM according to their needs following some guidelines and can adapt it for the different project phases. For example, if the user wants to analyze a project in the tender phase, the BoM template will have to be adapted accordingly. This means that not all life cycle stages and/ or material positions will be covered or given a value in the early design stage. For example, the construction site and therefore the groundworks might not be known yet and will not be included in the BoM (e.g., soil and gravel volumes will be set to zero).

The created BoM template in this branch-joint project was based on the rules in the PCRs for bridges and roads. PCRs must be followed in order to compare the EPDs for infrastructural constructions with a similar function. The considered system boundaries have to be documented in a standardized layout for the EPD-report with the final results, which may be delivered to a client.

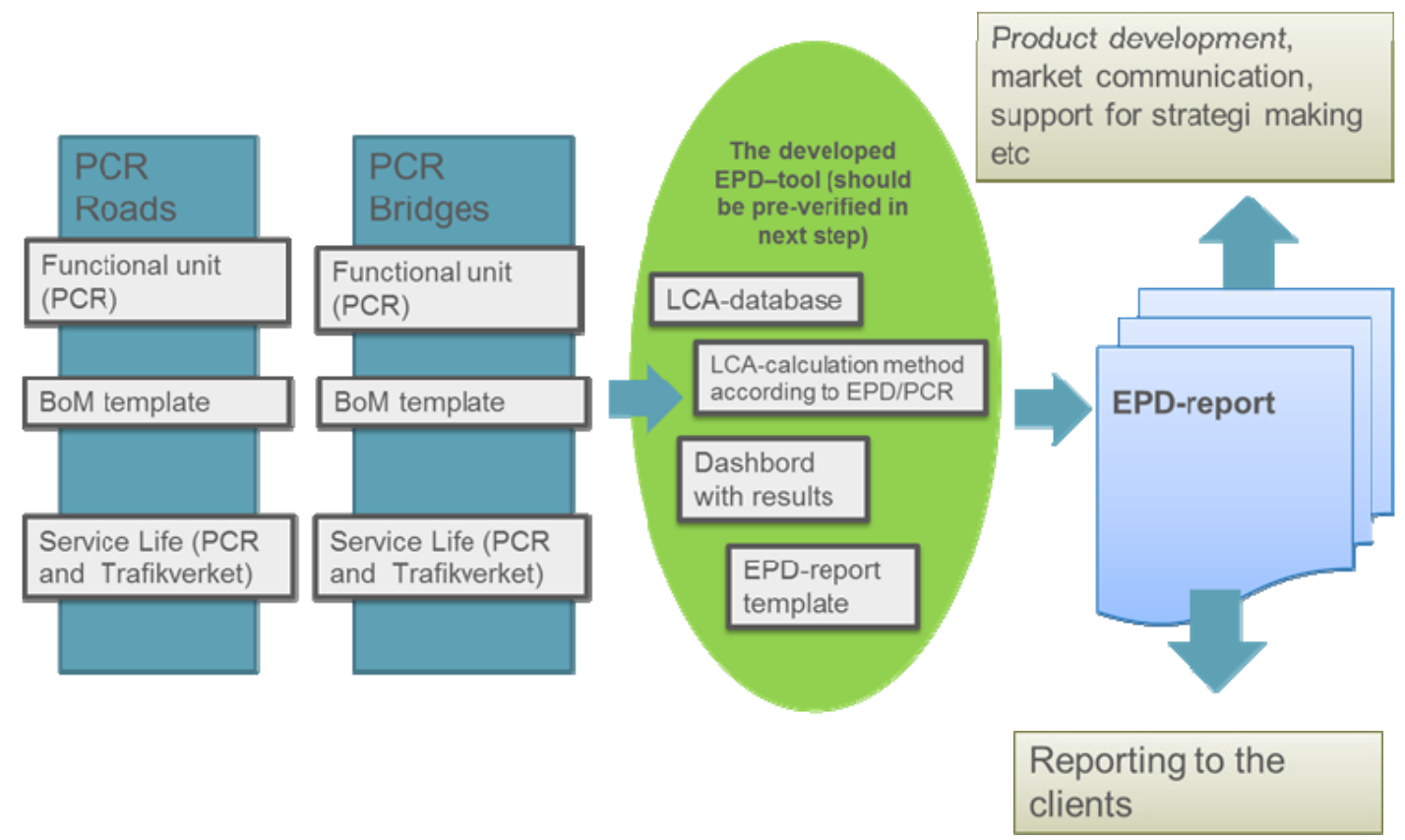

Fig. 1 The conceptual framework in a pre-verified LCA-tool which can produce verified EPDs and verified climate calculation (e.g., bridges and roads in this project). 


\begin{tabular}{|c|c|c|c|c|c|c|c|c|c|}
\hline $\begin{array}{l}\text { Upstre } \\
\text { Module }\end{array}$ & & $\begin{array}{r}\text { Core } \\
\text { Module }\end{array}$ & \multicolumn{6}{|c|}{ Downstream Module } & \multirow{2}{*}{$\begin{array}{l}\text { Other } \\
\text { environmental } \\
\text { information }\end{array}$} \\
\hline \multicolumn{3}{|c|}{ Construction } & Operation & Maintenance & \multicolumn{4}{|c|}{ End-of-Life } & \\
\hline 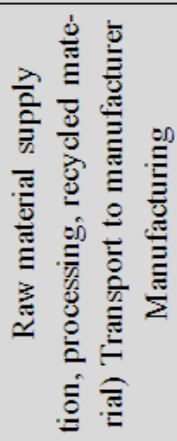 & 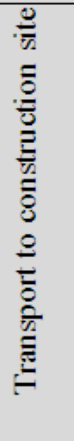 & 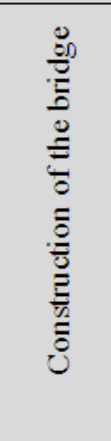 & 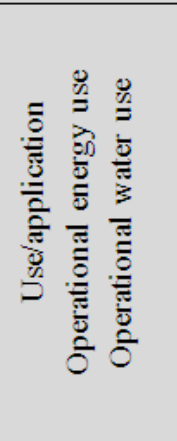 & 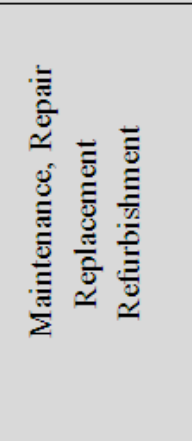 & 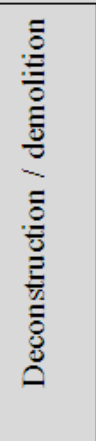 & 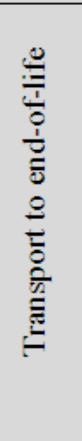 & 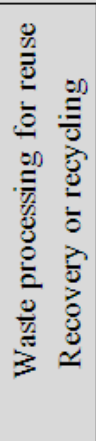 & 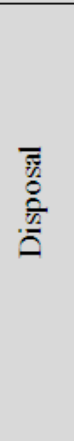 & 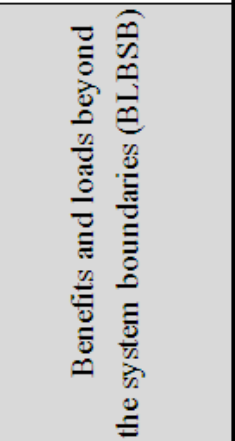 \\
\hline A1-A3 & A4 & A5 & $\mathrm{B} 1, \mathrm{~B} 6, \mathrm{~B} 7$ & B2-B5 & $\mathrm{C} 1$ & $\mathrm{C} 2$ & $\mathrm{C} 3$ & $\mathrm{C} 4$ & $\mathrm{D}$ \\
\hline $\mathrm{x}$ & $x$ & $\mathrm{x}$ & MND & $x$ & MND & $x$ & $\mathrm{x}$ & $\mathrm{x}$ & $\mathrm{x}$ \\
\hline
\end{tabular}

Fig. 2 System boundaries of the BoM template for the tested infrastructural projects $(X=$ declared $\operatorname{module} ; \mathrm{MND}=\operatorname{module}$ not declared).

\subsection{Data Availability in the Project Planning IT-Systems}

Swedish construction companies use various IT-based internal systems to store the project-specific information. In one of these systems, cost calculation systems entrepreneurs use to create a spreadsheet with the planned purchase of building materials and machine hours for each infrastructural project. It is important to note that these cost calculation systems have been developed to be able to make a very rough estimation of project costs. A cost calculation is usually updated during the various projects' stages: tender, design and production.

In some isolated cases, the spreadsheet with the project cost can be updated after the commissioning of the participants provided information and data collection about the construction stage of their infrastructural projects (including materials, transport to construction site and construction site works) from their project cost estimation IT-systems. Even the material and energy flows for the operation and the maintenance were added in the BoM template. The material flows have been collected for Modules
A1-A3 and the energy and operating materials' flows for B2 according to the PCR's requirements for bridges. Since no specific information about the allocation of materials in the maintenance phase is given in the PCR for roads [7], the same approach as for bridges [8] was used. Energy carriers and water use are allocated to B2.

It was made some general assumptions on the end-of-life scenarios, e.g., the amount of material to landfill, incineration and recycling. Module C1 (demolition, deconstruction) was not considered in the used BoM template, since no detailed data (e.g., energy, water, etc.) was available in the current project planning IT-systems. The project participants had to perform a lot of manual modifications of the existed project data from their cost calculation systems to match the requirements by EN 15804, EN 15978 and PCRs. Another important aspect is that the selection and comparison of design options is currently conducted in the design software such as AutoCAD, Revit, etc. Some construction companies try to link the analysis of design options in the $\mathrm{CAD} / \mathrm{BIM}$ software and the cost calculation system in 
"real time". This is far from a standardized workable routine in the industry.

\section{Conclusions}

\subsection{Automatization of Data Collection}

Contractors' internal IT-systems for monitoring of infrastructural projects (e.g., cost planning system) have a different data structure to store project information, which is not compatible with EPD/PCR's requirements. There is also a need for a technical solution to collect this missing project-related information, which is required for LCA in an EPD-format. At the moment, the data collection for climate calculations requires a manual handling. Some standardized routines and support to collect data for the entire life cycle of engineering works should be established in the construction companies. This will support an unbroken information flow with LCA-data between different market players.

The spreadsheets in the existing cost calculation systems usually contain fragmented input data for the Modules A1 to A3. Data collection for other modules is even more difficult to collect from the current project planning IT-systems. Data for the operation and the maintenance, percentage of recycled content in building materials, the transportation of building materials to the construction site are examples of input data for LCA-calculations, which are not stored in these IT-systems. There are various proposals on how this would be done in the future, for example, as part of the information in the BIM (building information model).

High cost to produce EPDs for materials/building parts/infrastructural projects discourages the broad-wide use of EPDs. The automatization of a data collection process can be achieved by integration of the pre-verified LCA-tools into existing practice with design planning in infrastructure projects. This will reduce the cost for creation of project-specific EPDs and climate declarations.

\subsection{Uncertainties with Using an EPD-Format}

EPD is an environmental declaration of the final product. Adoption of the EPD-format to set up, measure and follow-up operational goals for an infrastructure project should be developed. There are also some uncertainties with using EPDs as a verification of the environmental performance for a project design in the early stages. For the early planning stage or the tender phase, there should be an industry-wide agreement with listed assumptions regarding the system boundaries (e.g., level of detail on the bill of materials) and generic emission factors to be used for different materials/construction parts.

It is also unclear in the current PCR/EPD-system how to aggregate single EPDs for some main construction elements (tunnel, bridge) to calculate the total environmental impact of the entire infrastructural project. Harmonization of the various functional units, assumptions, etc. in different PCRs for civil engineering structures (bridges, tunnels, etc.) must be standardized by ISO/EN. It would be a great practical benefit to include bridges, tunnels and even a few more engineering structures in the scope of the same PCR.

PCRs are available for engineering constructions (e.g., bridges, highways, etc.) and construction materials and services. However, each PCR is linked to a particular EPD program operator (e.g., EPD-system Norway or the International EPD $^{\circledR}$ System in Sweden). EPDs from different operators are not comparable yet. The calculation rules for, e.g., carbon dioxide emissions differ between the current EPD-systems in Europe and USA, which can be misleading when comparing EPDs for products and processes. However, this is already addressed within the framework of the EPD/PCR and also within the ongoing work in the EU-project [10].

Reporting according to the EPD-format includes a mix of accounting and consequence LCAs. For example, Module D of an EPD is such a "consequence 
LCA", where all potential missing emissions and "credits" to other product systems should be reported. Even for the use phase, various potential usage scenarios far ahead in time, for example a particular source of energy, should be disclosed. The verification rules for these future potential scenarios for the use/ maintenance and the end-of-life phase are still unclear in the PCRs.

\subsection{More Tests Are Needed}

The contractors and material suppliers start climate optimization of their product and solution as well as optimization of the supply chain often as a part of an internal strategical work with energy usage and climate impact reduction. An innovative climate-efficient solution is often created by contractors long before the actual bidding process. Verified LCAs and climate calculations performed in an EPD-format will support contractor's internal work with the supply chains, support internal product optimization and in the same time allow reporting to the client according to the same LCA-calculation principles. In this case, the material suppliers and contractors do not need to disclose the recipe for their innovative products and designs, but a third party will audit and evaluate the quality of the provided LCAs and climate calculations. EPDs are the only LCA-format, which is recommended for using in procurement to evaluate and compare alternative designs according to the European standards [11].

A greater transparency through reporting of the climate impact from infrastructural projects in accordance with the internationally established standards will stimulate the development of innovative environmentally friendly products.

During this joint project, it was foreseen that the participants test some testing examples for one design scenario. More testing scenarios should be developed in the next step (early design, tender, planning, production, additional works and reporting to the client). This project was the very first step in establishment of a framework for calculation of the actual climate impacts for engineering works.

Benefits for the industry from this joint project are more knowledge on the existing gap between the long-term overall planning by the EU, the Swedish government, the ongoing standardization work and the contractor's practical work on climate issues in engineering projects. The project has also identified and clarified the requirements for the continued industry-wide cooperation in the development of verified comparable calculations of the climate impact for civil engineering structures.

\section{Acknowledgments}

This industry joint project was initiated in early 2013. The project is partly financed by The Development Fund of the Swedish Construction Industry (SBUF), STA and several Nordic contractors, material suppliers, industry joint associations and clients.

Participants in the project express gratitude for the opportunity that SBUF has given the construction industry by funding the project. Special thanks to the Infrastructural committee at SBUF.

\section{References}

[1] The Swedish Government. 2012. Fossiloberoende Fordonsflotta-ett steg på Vägen mot Nettonollutsläpp av Växthusgaser. Dir. 2012:78 (in Swedish)

[2] Trafikverket. 2016. "Klimatkalkyl—Infrastrukturens Klimatpåverkan och Energianvändning i ett Livscykelperspektiv." Accessed March 8, 2017. http://www.trafikverket.se/klimatkalkyl. (in Swedish)

[3] Johannessen, A. K. 2016. "Customer Demands on LCA in the Asphalt Industry in Norway." Presented at the Workshop at the Joint Project, Norwegian.

[4] The International EPD ${ }^{\circledR}$ System. 2016. Homepage. Accessed March 8, 2017. http://www.environdec.com/.

[5] EN 15978:2011: Sustainability of Construction Work-Assessment of Environmental Performance of Buildings-Calculation Method.

[6] EN 15804:2014-07: Sustainability of Construction Works-Environmental Product Declarations-Core Rules for the Product Category of Construction Products.

[7] PCR. 2013. Highways (except Elevated Highways), 
Streets and Roads. Version 1.02: 2013:20. UN CPC 53211.

[8] PCR. 2013. Bridges and Elevated Highways. Version 1.0: 2013:23. UN CPC 53221.

[9] Thinkstep. 2016. Homepage. Accessed March 8, 2017. https://www.thinkstep.com.

[10] Eco-platform. 2016. Homepage. Accessed March 8, 2017. www.eco-platform.org.

[11] ISO/TR 14025: 2000 Environmental Labels and Declarations-Type III Environmental Declarations. 